\title{
The Design of Instant Concreting Hollow Girderless Floor
}

\author{
Hui Lv ${ }^{1}$, Xin-fu Chen ${ }^{1}$
}

\author{
Jiangxi Institute of Economic Administrators, Jiangxi, Nanchang 330088
}

Keywords: Building materials; thin walled corrugated pipe; quasi plate method; structural analysis Abstract: looking for energy saving, high efficiency, high ratio of performance to price of building materials as hollow no beam floor mould box has been structure designers attention hot spot. In recent years, the study of the pre embedding of the corresponding inner membrane, the domestic and foreign scholars have done a lot of research work and put forward different building materials. In view of the existing thin wall corrugated pipe, the Jiangxi Jiang Feng Industrial Co., Ltd. the new plant full use of thin wall corrugated pipe as hollow no beam floor mold box as an example of the design of beamless roof using pseudo plate method for stress analysis of the reinforcement and the introduction, and computerization of basic steps and results analysis of the rationality of and through finite element introduced hollow girderless floor and equivalent solid non beam floor in the force moment differences that hollow girderless floor structure analysis method should be considered in the hollow effect, can also through area is considered in the weight. At last, it analyzes the shortcomings of the research and makes a prospect of the future research.and safety performance of structures after earthquake effect has been a hot topic of scholars.In view of the problem of how to build a rational damage model assessment method after earthquake effect.In recent years,domestic and foreign scholars have done a lot of work and different damage models are put forward.This paper analyzed present damage models from three levels of material,element and structure.Based on the analysis of its deficiency as well as made a prospect for the future research work.

\section{Introduction}

The 18th CPC National Congress_clearly pointed out adhering to the road of new urbanization with Chinese characteristics, and the basic characteristics of new urbanization are integrating of urban and rural, conservation of energy, Eco-suitability of human settlement, harmonious development, and so on. The major task in front of us now is, how to quickly promote the new urbanization, which requires us to integrate the concept and principles of ecological civilization into the whole process of urbanization, and take a road of new urbanization with intension, intelligence, proenvironment and low-carbon. Through the construction of a new rural community as a carrier, and to upgrade, transform into a breakthrough, promote urban construction infrastructure to rural development, and vigorously develop energy-saving, environmental protection of green buildings, plans for the next 8 years, the proportion of urban green construction will account for $50 \%$, which will provide a strong impetus for the development of green building. At present our country forest resources destruction is increasingly serious, the wood is short, the wood structure is obviously very difficult to develop rapidly. For the protection of farmland, the construction of the use of clay brick, so the masonry structure is also reduced; steel structure is in high speed development, but the cost is high, fire resistance is difficult to be widely used; housing construction engineering should be used more or reinforced concrete structure. The development of reinforced concrete structure has brought about a large number of resources such as steel, cement and other resources, resulting in a serious shortage of resources in China, a large number of materials caused by a huge amount of pollution, which is of course not in line with the construction of environment-friendly, resource-saving society and sustainable development of the road. Therefore, the development of energy saving concrete structure is one of the methods to solve these problems.

\section{Cast-In-Place Beamless Floor Technology Development}

With the continuous development of Chinese construction industry, more and more new structures, 
new energy-saving materials and new technologies emerge in the architectural engineering field with more and more problems also. Due to the higher requirements of the height of buildings, large space, seismic, light weight, flexible interval and other aspects[1], structural engineers proposed cast-in-place reinforced concrete girderless floor which can meet the requirements of large space, and widely applied this structure in many structure systems such as basement, production workshop and large span buildings. However, the character of large thickness of the floor slab causes the great permanent load of the whole structural system, which requires the greater structural reinforcement and larger relative column cross section and causes more wasting problems.

In recent years, structural engineers and researchers put forward no beam hollow floor system, which decorates a certain number of precast hollow permanent housing in existing cast-in-situ reinforced concrete flat beam floor, and the main kind of box material is the building materials whose bulk density is less than the concrete. The cast-in-situ concrete hollow flat slab floor has advantages of large span ,large space, light weight, small earthquakes , high performance-price ratio, and saving a lot of concrete material, which conforms to our national long-term strategic requirement of green building, energy conservation and emission reduction, and has great prospect of social and economic benefits[2]. As an important innovation achievement in building structure field in China, the cast-in-situ concrete hollow flat slab floor will become one of the important choices of floor structures in architectural structures in new century, and has huge market potentials, good social and economic benefits, and wide prospect in the future. The engineering training center in Jiangxi Agricultural university and the new-built workshop in Jiangxi Jiang Feng Industrial Co., Ltd., plan to use the technology, as shown in Figure 1 and figure 2.

The cast-in-situ concrete hollow flat slab floor is compose of a solid flat beam, hollow slab band and side beam composition, and hollow slab structure generally consists of a top plate, a bottom plate, and the middle rib beam. In order to make the concrete floor to produce regular cavities, the general method is to embedded corresponding lining before pouring concrete. We usually adopt the hollow cylinders, hollow cube boxes or regular solid light materials as the intimas[3-5]. For hollow cylinder materials, there are many problems such as plate fixing, and weak adhesive force of contact surface of outer walls and cast-in-situ concrete. And for cube hollow box or regular solid light materials, the floor plate of girderless hollow floor slab will easily cause cavities. The research of thin metallic bellows can resolve the above-mentioned problems. The cast-in-situ beamless floor with thin metallic bellows can gain greater hollow ratio for the size of cube intima is great larger than the sectional dimension of ribs, therefore the intima can take up more space and get more hollow rate; the rib spacing q quantity of reinforcement and sectional dimension of the cast-in-situ beamless floor are basically identical in whole building, which is advantageous to the construction. The outcome and application of the cast-in-situ beamless floor will become a new page in the development of concrete floor, the characters of energy conservation and material saving comply with national development trend of green building and have broad application prospect.

At present, the cast-in-site hollow concrete floor system has a fast-development in our country, the design and construction technology gradually becomes mature, and obtains good technical and economic effects.

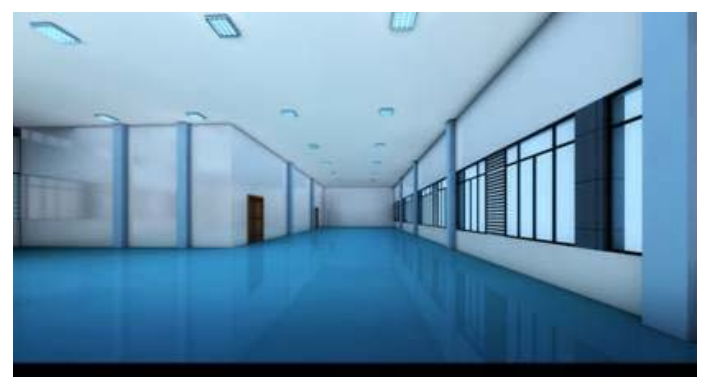

Figure 1 the engineering training center in a university in Jiangxi province 


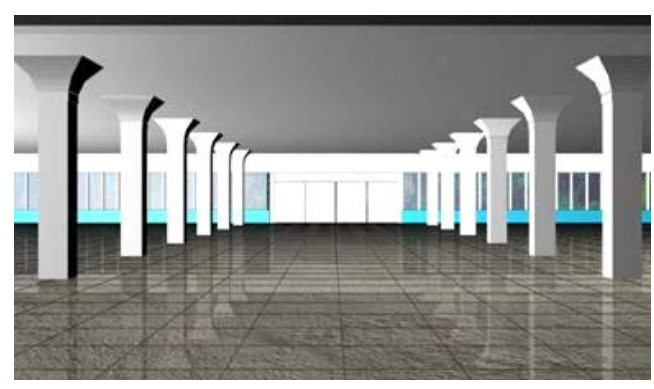

Figure 2 Jiangxi Jiang Feng Industrial Co., Ltd. indoor effect of the new plant

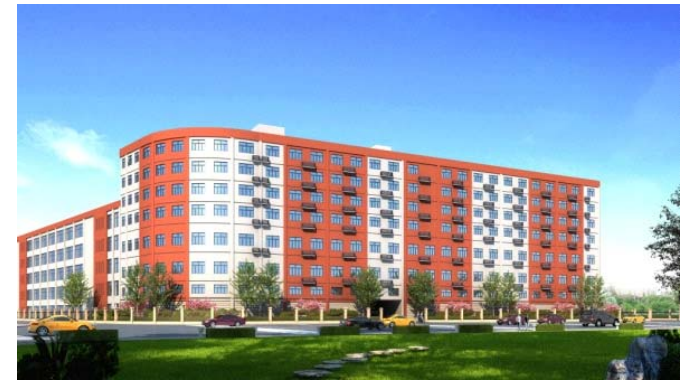

Figure 3 Jiangxi Jiang Feng electric vehicle new plant aerial view

The cast-in-site hollow concrete floor system(thin metallic bellows) is a hollow floor structure composed of hidden beam or visible beam, intima in thin metallic bellows, hole between the ventral rib, hole top, the cast-in-situ concrete slab in the bottom of the hole and other components, the castin-place concrete structure is formed after concreting. There are two difficulties in construction process: anti-floatage fixation and compactness of concrete at the bottom of plate.

According to the new plant in Jiangxi Jiang Feng Industrial Co., Ltd., this paper detailedly introduces the construction technology process of the hollow floor thin wall corrugated pipe, in order to provide a reference to the relevant technicists and management personnel.

\section{Engineering Survey}

This project is the new plant in Jiangxi River peak electric car, the total construction area is $29100 \mathrm{~m}^{2}$. There are five layers above-ground and 1 subterranean layer, the total height of the building (from the ground to the roof outside) is $23.70 \mathrm{~m}$, the basement height is $5.1 \mathrm{~m}$ (as a use of garage), the height is $4.5 \mathrm{~m}$ of 1 st layer, $4.2 \mathrm{~m}$ of $2 \mathrm{nd}$ or 3rd layer, $5.1 \mathrm{~m}$ of 4 th or 5 th layer. The five above-ground layers are used as the storage of production workshop.The construction of plant adopts plate-column structure, the whole building uses beamless hollow floor and raft foundation, which associates all the independent foundation under column with the contact beam, and pouring the whole foundation. The structural safety grade is second class, and the design life is 50 years. The design grade of foundation is $\mathrm{C}$ level, and architectural fire resistance rating is first level, basement waterproofing rank is second level, seismic fortification intensity is 6 degrees, design basic earthquake acceleration is $0.05 \mathrm{~g}$, classification of design earthquake is the first group, this project is $\mathrm{C}$ class construction according to the seismic fortification standard classification division, frame aseismic level is third level, the building site categories is second class, the characteristic period of the site is $0.35 \mathrm{~s}$, structural damping ratio is 0.05 , the surface roughness degree is class $\mathrm{B}$, basic wind pressure is $0.45 \mathrm{kN} / \mathrm{m}^{2}$, basic snow pressure is $0.40 \mathrm{kN} / \mathrm{m}^{2}$. The foundation soil and groundwater have weak corrosive to concrete and steel bar in concrete structures.

\section{Structure Design}

Due to the stringent requirements of clear height of the production process of the project, all layers must use the hollow flat slab floor structure system, the load as shown in table 1 , the mould box 
used in this project adopts the thin metallic bellows independent researched and developed by Jiangxi Jian You Technology Co., Ltd, the detailed arrangement are shown in figure 4.

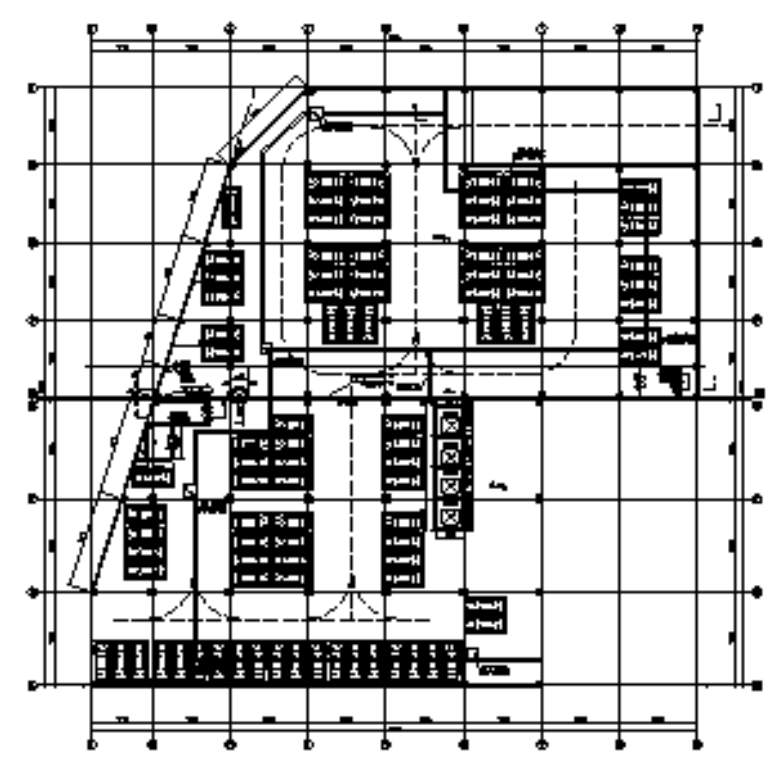

Figure 4 plan

The structural analysis of the plant uses PKPM software, the earthquake action of this project is calculated according to 6 degrees, and the seismic structural measures are 6 degrees, according to GB50011-2010 "building seismic design code", and the seismic grade is third level. The total size of axial net is: $77756 \mathrm{mmx} 77060 \mathrm{~mm}$, workshop column, $10000 \mathrm{~mm} 12040 \mathrm{~mm}$, $10000 \mathrm{mmx} 10000 \mathrm{~mm}, 800 \mathrm{mmx} 800 \mathrm{~mm}, 750 \mathrm{~mm} \times 750 \mathrm{~mm}, 950 \mathrm{mmx} 950 \mathrm{~mm}, 650 \mathrm{mmx} 650 \mathrm{~mm}$, $400 \mathrm{~mm} \times 1000 \mathrm{~mm}, 70 \mathrm{~mm}, 400 \mathrm{~mm} \times 1100 \mathrm{~mm}, 400 \mathrm{~mm}, 250 \mathrm{mmx} 600 \mathrm{~mm}, 350 \mathrm{~mm} \times 1000 \mathrm{~mm}$, $1200 \mathrm{mmx} 400 \mathrm{~mm}, 1000 \mathrm{mmx} 400 \mathrm{~mm}, 250 \mathrm{~mm}, 80 \mathrm{~mm}, 300 \mathrm{~mm}$, and $2500 \mathrm{~mm} \times 2500 \mathrm{~mm}$, the thickness of the slab is $120 \mathrm{~mm}$.

The plate fitted with reinforcing bars is analyzed with pseudo-plate method, the detailed results are shown in figure 5 and figure 6.

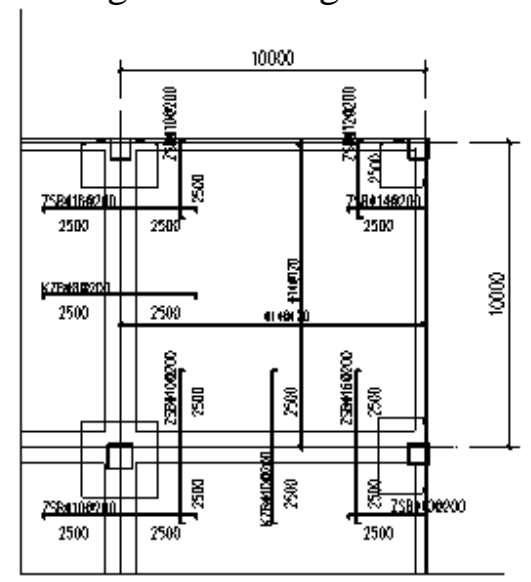

figure 5 plate fitted with reinforcing bars

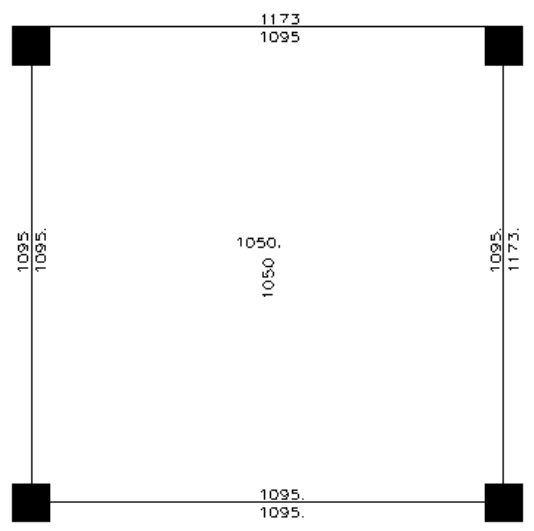

figure 6 the computation values $\left(\mathrm{mm}^{2}\right)$

\section{Finite Element Analysis}

We adopt elastic finite element method to analyze the hollow flat plate floor without post cap(thin metallic bellows) of the axis net, the grid is $10 \times 10 \mathrm{~m}^{2}$, namely two directions have the same plate grid, plate thickness is $400 \mathrm{~mm}$, pore diameter is $250 \mathrm{~mm}$, concrete strength grade is C30 and vertical uniform load calculation value and is completely consistent with the design values. Only the calculation of the intermediate plate is introduced here. In order to simplify the discussion, the 
calculation model of the intermediate plate is shown in the case of ignoring the concrete in the end duct. In order to contrast, the solid plate of same calculation model is also analyzed. We use the general elastic finite element software, adopt the isotropic plate element for the solid plate and solid plate area grid and anisotropic plate element for the hollow plate area grid. The whole plate grid is divided into 57900 units, each unit is $300 * 300 \mathrm{~mm}^{2}$. Through the analysis, the bending moment diagram of the middle plate, the plate and the plate, the plate and the plate are given. Table 2 lists section moment and slab hollow floor and solid slab with bending moment.

So it can be seen, there is little difference between solid slab and hollow floor flexural bearing capacity, however, the weight of the hollow floor is 30\% less than solid floor , which not only reduces the amount of material, but also reduces the project cost. Comparative analysis of the corner of the lattice grid floor also show the same results. Therefore, it has practical engineering significance to promote the application of hollow floor in large bay multi structure.

\section{Conclusion And Prospect}

This paper briefly discusses the development process and technological innovation of the hollow floor, and according to full using of girderless hollow floor in the new plant in the Jiangxi Jiang Feng Industrial Co., Ltd, we adopt the pseudo-plate method to discuss the force analysis of reinforcing bars, and give specific introduction of basic steps of computer calculation and the reasonable analysis of results, we also introduce the difference of stress bending moment between the girderless hollow floor and the solid flat beam floor of same amount, which proves that the influence of the hollow should be considered in analysis of griderless hollow floor or the actual areas can be converted according to the weights of plates.

At present the calculation theory and design method of the hollow floor is not mature enough, in order to promote the structure system, the further test and research of the basic mechanical performance of hollow floor should be taken to reveal the actual stress and deformation performance of hollow floor, and enrich the calculation and design theory of hollow building cover.

\section{Acknowledgements}

Fund Project: Jiangxi Provincial Department of Education Science and technology research (Major) project funding number: (LQ14E080005).

\section{References}

[1] Qiu. A cast-in-situ concrete hollow floor China [M]. Beijing: Construction Industry Press, 2007:1-236.

[2] Huang Chengruo, Zhou Yi and Leijiang. Prestressed no beam floor technology economic indicator analysis [C]. Beijing: China Academy of building research, 2004:491-498.

[3] Now Beijing pouring concrete hollow floor structure technical specification for CECS175:2004[S].: China Association for engineering construction standardization concrete structure Professional Committee, 2004.

[4] Code for design of concrete structures [4] Beijing: GB500102010[S]. Chinese Building Industry Press, 2010:23-27.

[5] Technical specification for concrete structures prestressed JGJ922004[S]. China Beijing: Construction Industry Press, 2004

[6] Zhang Weirong. The cast-in-situ concrete hollow floor structure design and construction technology research [D]. Beijing: Beijing University of Technology, 2008:5-11.

[7] Yu Yu. Study of [D]. prestressed concrete hollow floor reasonable method of calculating the ultimate bearing capacity of Hunan: Central South University, 2009:3-52. 
[8] Building seismic design code GB50011-2010[S]. Beijing: China Building Industry Press, 2010:7.3-2010[S]. JGJ Beijing: China Building Industry Press, 2010:9.

[9] Concrete structure design specification GB50010-2010[S]. Beijing: China Building Industry Press, 2010:4.

[10]R.Park and W. L.Gamble Reinforced, Concrete Slabs[J] John, Wiley\&amp;Sons.1980:6-7.

[11]H.M.Westergaard and WA.Slater Moments, and Stresses in Slabs[J] 1921,17, [12] (3):415-538.

[12]David S.Hatcher Mete, A.Sozen and, Chester ESiess:Test of Reinforced Concrete Flatplate[J].ASCE [13], 1965,91 (5): 22-27.

[13]David S.Hatcher Mete, A.Sozen and, Chester ESiess:Test of Reinforced Concrete FlatSlab[J], ASCE, 1969,95 (6): 27-33.

[14]Sidney A.Guralnick and Robert WLa Fraugh.Laboratory Study of a 45-Foot Square FlatPlate Structure[J].Journal of the American Concrete [15] Institute 1963,60, (9): 57-63.

[15]Kenneth Leet Reinforced, Concrete Design[J].Graw-Hilt Company USA, [16], 1982

[16]Kenneth Leet Reinforced, Concrete Design [J] (Edition Second) Graw-Hill, Company USA, 1990

[17]Wang Qunyi, Xue Guoya, Song Qigen. Stress distribution of the RC beam under local load are analyzed by [J]. Journal of Southeast University,.1994, 24 (3): 13-19.

[18]Zhang Yufeng, Lv Zhitao. Influence of [J]. on the width of the plate column structure,.2001,31 (2): 43-46.

[19]Wu Jing [D], research and design of high-rise building unbonded prestressed slab floor system. Nanjing: Southeast University, 1999:5. 